\title{
A reappraisal of Baskerville's Greek types
}

Book or Report Section

Accepted Version

Leonidas, G. ORCID: https://orcid.org/0000-0003-0468-6268 (2017) A reappraisal of Baskerville's Greek types. In: ArcherParré, C. and Dick, M. (eds.) John Baskerville: art and industry in the Enlightenment. The University of Liverpool Press, Liverpool, pp. 133-150. Available at https://centaur.reading.ac.uk/55092/

It is advisable to refer to the publisher's version if you intend to cite from the work. See Guidance on citing.

Publisher: The University of Liverpool Press

All outputs in CentAUR are protected by Intellectual Property Rights law, including copyright law. Copyright and IPR is retained by the creators or other copyright holders. Terms and conditions for use of this material are defined in the End User Agreement.

www.reading.ac.uk/centaur

\section{CentAUR}

Central Archive at the University of Reading

Reading's research outputs online 


\section{Introduction}

John Baskerville's position in typographic history is assured by his contributions to the technology of printing, and the style of his original typefaces, which defined the Transitional category in established classifications. Baskerville also cut a Greek typeface for the University Press in Oxford, for which he is rather less well-known. At that time the printing of Greek texts continued to be central to scholarship and discourse. The typography of Greek texts could be characterised as a continuation of French models from the sixteenth century, with a gradual dilution of the complexity of ligatures and abbreviations, mostly through printers in the Low Countries. In Britain, Greek printing was dominated by the university presses, which reproduced conservatively the continental models - exemplified by Oxford's Fell types, which were Dutch adaptations of earlier French models. Hindsight allows us to identify a meaningful development in the Greek types cut by Alexander Wilson for the Foulis Press in Glasgow in the middle of the eighteenth century, but we can argue that at the time that Baskerville was considering Greek printing the typographic environment was ripe for a new style of Greek types.

Baskerville's Greek typeface was used for two editions of the New Testament printed in 1763: a quarto in 500 copies, and an octavo in 2000 copies - and never again thereafter. The typeface maintained the cursive ductus of earlier models, but abandoned complex ligatures and any hint of scribal flourish. He homogenised the modulation of the letter strokes and the treatment of terminals, and normalised the horizontal alignments of all letters. Although the strokes are in some letters too delicate, the narrow set of the style composes a consistent, uniform texture that is a clean break from contemporaneous models. It is arguable that this is the first Greek typeface that can be described as fully typographic in the context of the technology of the time. It sets a pattern that was to be followed nearly a century and a half later, without acknowledgement, when the classicist Richard 
Porson's hand was used as a model for a new Greek typeface for Cambridge University Press.

The types attracted lukewarm comments by near contemporaries, and even dismissive comments by notable later reviewers. Recent historians of Greek type offer only a passing mention, reflecting the relative obscurity of the two editions in the Greek typographic corpus ${ }^{1}$. John Bowman reasonably speculated that the typeface's lack of popularity with contemporary commentators may go some way towards explaining its scarcity in the reference narratives of Greek typographic development. ${ }^{2}$ These days, the original Baskerville Greek is practically unknown, although a Greek typeface with the same name - but no stylistic connection whatsoever - has been a staple of printing within Greece since its introduction in the early 1970 s for phototypesetting, and its subsequent re-engineering as a digital font, for $\mathrm{Li}$ notype typesetters and platform-independent environments.

Conventional evaluation techniques focus on an analysis of the forms of the letters in the typeface, their fitting in composed paragraphs, and an examination of the typeface in the context of its use. Indeed, this approach can provide some insights into the considerations that may have informed Baskerville's choices. However, this would not suffice to explain the controversial rejection of the typeface, since it can be shown that Baskerville's typeface had solid roots in the gradual simplification of Greek typefaces that had been under way for decades ${ }^{3}$, that contemporary commentators would have been aware of. Neither is it possible to establish that the typeface's absence is due to the prevailing attitudes for Greek printing in Oxford at the time, and the later impact of Porson's typeface on Greek typography.

On the contrary, the fate of the typeface seems to have more to do with the disapproval of commentators of the London-based establishment,

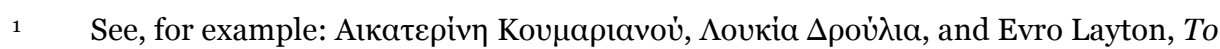

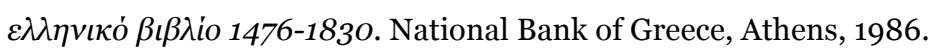

2 John Bowman, 'Greek typography: the English contribution' . Greek letters: from tablets to pixels, Michael Macrakis (ed.). New Castle: Oak Knoll Press, 1997, pp. 129-146. 3 John Lane, 'From the Grecs du Roi to the Homer Greek: two centuries of Greek printing types in the wake of Garamond' . Greek letters: from tablets to pixels, Michael Macrakis (ed.). New Castle: Oak Knoll Press, 1997, pp. 109-128.
} 
and Victor Scholderer in particular ${ }^{4}$. Scholderer was uncharacteristically blunt in his condemnation of Baskerville's Greek. The weight of his opinion sealed the fate of the typeface, with only careful counterpoints decades later. However, Scholderer may have not been entirely fair in his evaluation of the Baskerville Greek types, which have a far richer story to tell than his dismissal suggests.

4 Scholderer (1880-1971) was the successor of Robert Proctor at the British Museum. He worked on the bibliography of early printed books, and spearheaded the compilation of the Museum's catalogue of incunabula. 


\section{Gradual simplification, and rapid innovation}

Baskerville's Greek types (image 1) are dominated by their overall narrow proportions, and the moderate contrast. The texture is light relatively to the Greek typefaces of the time, and letters align horizontally with notable consistency. Most of the letters fit within a smaller range of widths, and there is an almost complete absence of ligatures. Some forms maintain a cursive structure (e.g. the gamma and theta) but alternate forms are greatly reduced. The overall impression is of an altogether more homogeneous style, albeit lighter and more typographic than contemporary types.

Indeed, the most notable near-contemporary Greek typeface is the range of sizes cut by Alexander Wilson for the Foulis Press in Glasgow, from around 20 years earlier (image 2). Wilson's Greek is notable for the almost complete abandonment of ligatures, which much simplified the typesetting of Greek. It is characterized by an openness in the space between letters, and - compared to Baskerville - relatively inconsistent modulation, and looser horizontal alignments. Its style fits the pared-down typography of the Foulis Press, striking a balance between the cursive nature of the Greek script and the homogeneity expected in typographic work of the period5.

Both the Baskerville and the Wilson types are responses to a trend in Greek types that had been gaining momentum for nearly two centuries. Garamond captured the ornate calligraphic style of the scribe Angelos Vergikios in his Grec du roi types, used by Robert Estienne in his celebrated

\footnotetext{
5 The reputation of the Wilson Greek has been amplified in recent years by a digital revival designed by Matthew Carter for the definitive reference for Aldine editions. See Matthew Carter, Wilson Greek, Limited edition laser-printed specimen, 1995; and Nicolas Barker, The Aldine Press: Catalogue of the Ahmanson-Murphy Collection of Books by or Relating to the Press in the Library of the University of California, Los Angeles, Incorporating Works Recorded Elsewhere. University of California Press, 2001.
} 
editions for the French royal library. ${ }^{6}$ The convoluted style required a huge range of ligatures, complicating the typesetting of Greek, and initiating a gradual process of simplification. ${ }^{7}$ However, the conservative nature of printing Greek (of a limited range of texts, for a community of scholars or readers of religious texts) meant that there were no radical departures in the visible style of Greek types. Rather, printers abandoned the more complicated ligatures, varying their approach depending on the size of text being typeset, and the formality of the text. Already by the seventeenth century it is very common to see Greek texts with types in the style of the Grecdu-roi, but radically simplified character sets. Wetstein's pocket-sized Homer (1707) (image 3) is typical of the extremes of this approach. By contrast, Caslon's Double Pica Greek in his specimen of 1785 (image 4) maintains enough ligatures to hint at the elaborate style of the typeface, while fewer than one in six words include a ligature of more than two letters.

Narratives of Greek typography rarely compare editions from several printers across decades with a focus on typeface style and character sets, so the progression of the simplification of Greek character sets was under-represented. With the notable exception of John Lane ${ }^{8}$, Wilson's contribution tends to be overemphasised. However, a comparison of Wetstein's Greek and Wilson's smallest size, as used in a square octavo New Testament,

6 Hendrik D. L. Vervliet, The Palaeotypography of the French Renaissance: on Sixteenth-century typefaces, Volume 1. Brill, 2008, p. 365. The punchcutter Claude Garamond, active in the early and middle sixteenth century, cut typefaces that defined dominant typographic genres. His Greek typefaces represent the pinnacle of capturing in metal of a fluid written style. His contemporary Robert Estienne was a notable printer and scholar in Paris, and part of an important dynasty of printers associated with the printing of Greek. The editions of Robert and his son Henri became standard reference works for subsequent editions.

The main driver for this process was not only the additional investment in casting the hundreds of additional sorts, but the very practical problems of typesetting Greek from six or eight cases, rather than the usual two for Latin. An excellent resource for this is the section on typesetting in the Encyclopédie, ou dictionnaire raisonné des sciences, des arts et des métiers, Denis Diderot \& Jean le Rond d'Alembert (eds), Paris, 1751: Plate 3 shows the conventional two cases for composing with the Latin script, whereas Plates 4 and 5 show six full cases for composing Greek, almost entirely devoted to the ligatures and abbreviations required to reproduce the calligraphic Greek style.

8 John A. Lane, ibid. 
demonstrates that the texture of the two typefaces is nearly indistinguishable. 9

From that perspective, Baskerville's Greek is not an aberration, but a reasonable attempt to recognize existing practice in a new typeface. Whereas Wilson's Greek tries to keep close to the cursive style of the continental models, Baskerville's moves further towards a purely typographic script, homogenising alignments and the pattern of spaces and strokes. The narrow proportions are a reasonable response to the light modulation, since wider counters would render the texture overly light. From the point of view of inventing a Greek style that is informed by the style of the eighteenth century, Baskerville's Greek is a credible attempt.

Thirty years after Baskerville, the Didots in Paris and Giambattista Bodoni in Parma experimented along similar lines, cutting several Greek typefaces that attempted to make the script simple enough for efficient typographic composition, and consistent with the style of their high-contrast Latin typefaces. ${ }^{10}$ The Didot Greeks (image 5) evidence experimentation with vertical stress and relatively wide proportions, an approach that fits uneasily with the stroke structure of the Greek letters. This was quickly abandoned in favour of a variant stress angle, which is more accommodating of the multiple stroke crossovers and overlaps of the Greek script. Bodoni's Greeks (image 6) exhibit a greater range of styles, and far less confidence on how to adapt Greek typographic forms to a high contrast style: there is no clear resolution, but rather a collection of stylistic approaches.

In comparison, Baskerville's Greek hints at a keen eye for pattern and a sensitivity towards the Greek script's personality. The narrower proportions eliminate the thin horizontal strokes that Didot would abandon, and Bodoni seems to have struggled with. Arguably Baskerville's Greek typeface was too much of a departure from the style of Greek editions at the time, whereas by the time that Didot and Bodoni were cutting their Greeks there

\footnotetext{
$9 \quad$ Novum Testamentum. Foulis Press, Glasgow, 1759.

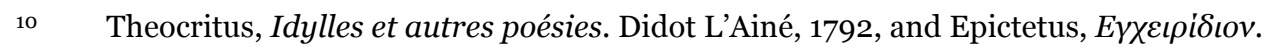
Giambattista Bodoni, Parma, 1793.
} 
was more space for experimentation (and, in the case of the Didots, a target market requiring modest affordable editions for scholars).

Notably, by the early years of the nineteenth century type foundries in Leipzig like Schelter \& Giesecke were producing Greek typefaces that were extremely close to Baskerville's style. They were often used in modest editions of classic texts for students and scholars, at small sizes in dense typesetting (image 7 ). ${ }^{11}$ The style of the editions is very different from Baskerville's New Testaments, but the typefaces follow a very similar approach to arrive at a modulated, cursive style. It has not been possible to establish whether continental typefounders at the time might have had copies of Baskerville's New Testament to hand, and even if there was a connection, it might be misleading. However, what there is ample evidence of is that Baskerville was introducing ideas into the design of Greek typefaces that were later echoed, explicitly or not, throughout Europe.

11 Lucian Samosatensis, Opera. Teubner, Leipzig, 1846. 


\section{Design and critique}

It is clear that the typographic characteristics of the two New Testament editions will have influenced responses to Baskerville's Greek types. With the exception of chapter headings and drop capitals, the justified text blocks have very little variation with each page. The capitals are somewhat heavy for the lowercase, hinting at roots in Baskerville's existing Latin types. This, however, highlights the problematic methodology of the long-established approach of imitating scribal hands for Greek types, rather than any shortcomings of the lowercase itself.

The quarto edition is close to the size of a lectern volume, which stretches out the typography. This creates a visual juxtaposition between large, open pages and the relatively narrow proportions of the typeface. Comparing Baskerville's Greek (image 1) with the Greek in Caslon's specimen (image 4) which has several letters of very generous proportions, the contrast is even stronger.

More important for a typographic evaluation of the types is the lack of their use in any other editions. Baskerville printed smaller octavo volumes where the narrow proportions of the Greek would fit more naturally; indeed the editions that are most commonly referenced as models for the use of his Latin typeface are fairly compact ${ }^{12}$. Additionally, Baskerville printed bilingual texts with Greek in a secondary role (embedded within the Latin script as a quote, reference, or annotation) with Greek types in the conventional style for the period. ${ }^{13}$ The narrower, more consistent style of his original Greek types suggests that a typographically more complex document would be a more appropriate context for their use.

\footnotetext{
12 Publii Virgilii Maronis, Bucolica, Georgica, et Aeneis. John Baskerville, Birmingham, 1766

13 David Jennings, An introduction to the knowledge of medals, John Baskerville for T. Field and J. Payne, London, 1764.
} 
The absence of the types from any other setting and the formality of the typography of the New Testament influenced views about the typeface. It is also arguable that the relative obscurity of the two volumes must have contributed to the lack of deeper analysis of the Greek types, and emphasised the repetition of secondary commentary. The result is that any reviews exist either in texts on Baskerville's wider work, or as mentions in general narratives on Greek typography. Furthermore, contemporary reviews are scarce, as are any texts written by Baskerville himself about the Greek.

The comments that do exist tend to record the strong personal opinion of the writer, but often without any analysis of the forms of the typographic context. One of the earliest references is by Mores, who is scathing:

'The Greek is execrable, indeed [Baskerville] can hardly claim a place among the letter-cutters'.${ }^{14}$ On the contrary, Dibdin is generally positive: 'The type [...] is large and distinct; and in both editions has an elegant effect' ; but does not comment further on the suitability of the types for other work. ${ }^{15}$ Reed is disparaging: 'The letter is neat, but stiff and cramped, and apparently formed on an arbitrary estimate of conventional taste, and without any reference to any accepted model'.${ }^{16}$ Reed makes a claim that would be echoed by Proctor, and sidesteps entirely the challenge of making the typographic Greek script efficient to typeset.

When Proctor turns his attention to the types, he recognises the important development of the small character set, but is damning with faint praise: 'decorus but dull, its monotonous regularity is certainly preferable to the abominable modern continental or Didot types' ${ }^{17}$ We can assume

14 Edward Rowe Mores, A dissertation upon English typographical founders and founderies. (Reprint of 1778 edition.) Harry Carter (ed.) Oxford University Press, 1963, p. 81.

15 Thomas Frognall Dibdin, 1808, An introduction to the knowledge of rare and valuable editions of the Greek and Roman classics (2nd ed.), p. LXIX. It is worth noting that this comment is in Dibdin's review of New Testaments; his extended discussion of Baskerville's contributions does not mention his Greek typeface at all.

16 Talbot Baines Reed, A history of the old English founderies, Elliot Stock, London, 1887, p. 61.

17 Robert Proctor, Robert Proctor, The printing of Greek in the fifteenth century, Bibliographical Society at the Oxford University Press, 1900, p. 147. The Didot types that Proctor is referring to are shown in image 5. 
that Proctor would be intimately aware of the de facto gradual simplification of the character set of Greek typefaces by continental printers, as well as Wilson's Greek for the Foulis Press. However, he does not extrapolate to the obvious question: if the ligatures that compose the calligraphic style of the older Greek types are eliminated, what is the effect on the forms and spacing of letters that are henceforth composed on their own? This is a fundamental problem for typefaces transitioning from calligraphic styles to more modularised typographic forms. It is possible to argue that Wilson sidestepped the issue, but keeping a fairly calligraphic style for the letters, and spacing them widely.

Neither does Proctor consider the suitability of Baskerville's Greek types for more complex typographic environments, such as reference works and editions with annotations. Given the time at which he writes, this may be intentionally short-sighted. At the very least Proctor would be intimately familiar with titles like Liddell \& Scott's Greek-English Lexicon, which demonstrate clearly the need for coordinated Greek typefaces of different styles and weights. ${ }^{18}$

Furthermore, Proctor introduces the comparison with the Didot Greeks, which - like Wilson's and Baskerville's, had no alternative letterforms and no ligatures to allow for efficient typesetting. They addressed the problem of increasing the modulation of the strokes by introducing a variant stress angle, a solution that had deep roots in the calligraphic Greek style. It is possible to argue that the Didot and Baskerville Greeks are equivalent alternative interpretations of the same typographic problem, but Proctor does not enter into any such analysis. He seems to have decided that the variant modulation of the French model is wrong, and presents it without justification. Although the Baskerville is not fully to his liking, it is closer to the consistency he expects.

Proctor's comments are important, not only because of his standing as a historian on Greek type. His Otter Type, first used in Aeschylus' Horesteia

18 For a discussion of the issues surrounding bilingual Greek reference works see Leonidas, G. (2012) CUP Intermediate Greek-English Lexicon. 
by Emery Walker, Sydney Cockerell, and A. F. Pollard in 1904, offered a different model for Greek typefaces (image 8). Proctor sidestepped the models of Kalliergis, Aldus, and Estienne, and based his Greek on a model drawing on the manuscripts of Moussaios, which was the source for the Greek types used for part of the 1514 Complutensian Polyglot by Arnaldo Guillen de Brocar. Proctor's claim that this is 'the only one of which it can be affirmed with certainty that it is based on the writing of a particular manuscript' 19 is controversial, given the manuscripts by Vergikios and others that Proctor certainly had access to in the libraries in London, Cambridge, and Oxford. These manuscripts not only establish the connection of the other typeface models to scribal examples, but also demonstrate the range of styles by Greek scribes. Indeed the range of styles evident in Greek manuscripts provides unambiguous evidence that not only were variant styles in parallel use, but that a single scribe would write in different styles depending on the formality and subject of the document. ${ }^{20}$

The tone set by Proctor was echoed by other writers. Writing in the Monotype Recorder, Hinds described Baskerville's Greek as an 'undistinguished effort on sounder lines than the Estienne Greek' and 'not particularly legible, and [...] feminine'.$^{21}$ There is no explanation why the French model is unsound, or what features diminish the legibility of Baskerville's type. As for the association with gender, is as meaningless typographically as it is characteristic of attitudes at the time. However, the presence of such statements in a widely circulated publication would make it all the more difficult to put forward alternative views.

Scholderer was not circumspect with his condemnation: in a publication he edited that would become a standard reference for Greek typography, he wrote that [Baskerville's skill,] 'which he had proved upon roman

\footnotetext{
$19 \quad$ Robert Proctor, ibid, p. 144.

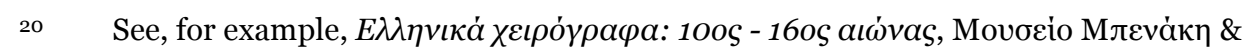
Institut de recherché et d'histoire des Textes, Athens 1991, and Repertorium der griechischen Kopisten 80o-16oo, Verlag der Österreichischen Akademie der Wissenschaften, Vienna 1989.

${ }_{21}$ George Hinds, 'Greek printing types' . Monotype Recorder, January-February 1916, p. 9.
} 
letter [...] failed him completely in his Greek, a mean-looking, spineless fount' . Scholderer made clear his views about what a Greek typeface should look like, when he wrote of Proctor's Otter Type that it was 'undoubtedly the finest Greek fount ever cut' $\quad{ }^{22}$ Notwithstanding the objection that other Greek types could also claim a connection to manuscript forms, Scholderer's view is one that reflects a particularly narrow perspective on typography: one where Greek typefaces are used to set mostly classical texts, in isolation or in parallel settings with their translations - and always with only a single language within each block of text. This view would have been barely credible at Baskerville's time, when Greek was regularly set in footnotes in a smaller size than the main text, and sometimes even in a different style altogether. By the early twentieth century, when Scholderer was writing, the range of printing in Greek was as rich as anything in English.

It is very likely that Scholderer's views on Baskerville's Greek type were influenced by his bias towards the style followed by Proctor. His own New Hellenic typeface (image 9), launched in 1927 by Monotype as Series 192 with a sample setting in the catalogue of an exhibition in the British Museum on the history of Greek typefaces, edited by Scholderer ${ }^{23}$ : is is closely based on the same sources as Proctor, and follows a similar approach to the design of the letters. The presentation of the New Hellenic reveals Scholderer's views about the typeface's intended use: the typeface is shown in a twin column setting of Thucydides for the 12 point, and a single column setting of Homer for the 18 point: both in a single style per page, without any English text alongside. The samples pages come at the end of an edition with an essay on the history of Greek typefaces, and reproductions (in superb collotype plates) of 60 notable Greek editions from 1465 onwards. The editorial intention seems to be that the history of Greek typefaces culminated with the New Hellenic. (Presumably Scholderer knew that since 1910 Monotype had been selling the Series 90 Greek, which was based

22 Victor Scholderer, Greek printing types, Trustees of the British Museum, 1927, p. 13 and p. 15 .

23 Scholderer, ibid. 
on the Didot model. He does not mention any of the existing Monotype Greek typefaces in the text; neither is any reproduced in the plates.)

Scholderer's New Hellenic was reviewed in the Fleuron (presumably by Morison). The reviewer was generally positive, but was clear about the limitations of its brief: 'our general printing still has a need of a Greek which shall sort agreeably with the romans and italics we are bound to use. We require an upright Caslonised fount which [...] shall be no more conspicuous on the page than is the italic.' ${ }^{24}$ Morison does not mention Baskerville's Greek in the review, but it is interesting to contemplate whether he would have accepted Baskerville's Greek as a member of a wider Greek family. Scholderer seems to have set the tone for commentary on Baskerville’s Greek. In 1943 McMurtrie writes that [Baskerville’s Greek] 'added nothing to his reputation' .25

It is only in 1960 that a more sensitive evaluation appears in one of the main reference sources. Writing in the Penrose Annual, James Mosley notes Mores' comment, but adds an interpretation altogether absent from commentators so far: 'Baskerville saw the Greek letters as a kind of italic, and made them conform [...] to his own slender and regular italic'.${ }^{26}$ This statement leads to a reasonable hypothesis: Baskerville was an accomplished writing master, and it is very likely that he wrote out passages of Greek before cutting the type. The structure of Greek letterforms is closer in ductus to the cursive than to upright Latin; indeed, Mosley's suggestion is in agreement with typeface designers' practice. ${ }^{27}$ Furthermore, writing Greek with a contemporary technique, as Baskerville was likely to do, would impart a gentle modulation, very similar to the one evident in the types. Extending Mosley's rationale, it is likely that Baskerville's typeface represents a response to the requirement for Greek that was more typographic, while also resonating with his ideas about re-interpreting existing models.

\footnotetext{
24 N.a., 'The New Hellenic' . In The Fleuron, no 6, 1928, pp. 231. Although the italic for Caslon follows a conventional cursive model, this review echoes Morison's views that Greek typefaces should follow the patterns of the Latin.

25 Douglas McMurtrie, The Book, 1943, p. 377.

26 'Porson's Greek types' , Penrose Annual, vol. 54, 1960, pp. 36-40.

27 John Hudson, Now read this, Microsoft Inc., p. 19.
} 
It is not clear whether Mosley's nuanced review signalled that a reevaluation was possible, or the passage of time had diminished the condemnation of Baskerville's Greek by Proctor and Scholderer. Regardless, Pardoe's biography of Baskerville includes an insightful comparison with Wilson's Greek: [Baskerville’s Greek] 'seems very acceptable. [...][Some] letters, individually, seem more pleasing than Wilson's, but comparing a page, Wilson's is better.' ${ }^{28}$ Earlier in the text Pardoe admits that he has no expertise in Greek, but this caveat is unnecessary: he detects correctly that Baskerville's letters are overall well-formed, whereas Wilson's maintain some of the inconsistency of written forms.

It is not clear which books by the Foulis Press Pardoe had in mind when he was comparing the typefaces (Wilson's Greek was cut in a range of sizes, and was used in books with considerable variety of typographic arrangements). Regardless, he is the first to compare explicitly the effect of typeset blocks of text. This is not only a more appropriate perspective for the discussion of typeface design, but also reveals a dimension of the critique that seems to have escaped most earlier commentators. We can interpret Pardoe's comment to mean that Wilson's Greek appears more coherent in blocks of text, whereas Baskerville's has a texture that is not typographically resolved. This may appear counter-intuitive, since Baskerville's Greek has a higher level of consistency between the letters. However, despite the relatively loose spacing and higher variability of forms, Wilson's Greek sits squarely within the set of typefaces with a close connection to written forms. This genre would have been well represented in any library with Greek editions in the eighteenth century: Wilson was not cutting his Greek types in a vacuum, but was developing a style along well-established axes. By contrast, Baskerville interpreted the written forms through the lens of a different tool, introducing an element of novelty to his typeface. In other words, Baskerville had no direct comparators for his typeface. Wilson's Greek represented the next link in a well-trodden path of gradual evolution,

28 Frank Ernest Pardoe, John Baskerville of Birmingham: letter-founder and printer, Frederick Mueller Ltd., London, 1975, p. 56. 
whereas Baskerville's presaged a style that would only be identified a few decades later, on the European continent. 


\section{Typefaces for a richer typography}

By the end of the eighteenth century Greek texts increasingly appear in editions with parallel translations (usually on opposite pages), and annotations at the foot of each page. The Greek typefaces in these books are characterised by an attempt to balance the optical size of letters for easy reading, with a character-per-line count that would not be too far off from the equivalent translation in Latin, English, French, or German. The annotations are overwhelmingly in two languages, with the Greek embedded within sentences in one of the other languages. ${ }^{29}$ Many of the editions were aimed at students, so a utilitarian, economical typography is very common. The expressive calligraphic strokes of traditional Greek typefaces occupy a lot of space (especially vertically, through their long ascenders and descenders) and require ample clearance for their prominent diacritics.

Baskerville's Greek assumes a more nuanced identity if seen as an early attempt to rethink Greek typefaces in a changing typographic environment. Although Baskerville's two New Testaments are anything but modest and compact, we can be certain that he was familiar with the more complex typographic environment in which Greek was increasingly appearing. (Indeed, the Introduction to the knowledge of medals referenced earlier was printed only a year after the New Testaments.) In this light Baskerville's

\footnotetext{
29 Jacobus Lectius, Poetae Graeci veteres carminis heroici scriptores... Avreliae Allobrogvm, Sumptibus Caldorianae societatis, 1606, and Heliodorus, Aethiopicorum, Apud P. Ludovicum Febvrier, Paris, 1619, exemplify editions where Greek and Latin are typeset in parallel columns with no annotations. The Polybii Lycortæ F. Megalopolitani Historiarum Apud Joannem Janssonium à Waesberge, \& Joannem à Someren, Amsterdam, 1670, demonstrates inline multi-script typesetting, where the calligraphic style appears too small. Footnotes and more complex arrangements are evident in Plutarch, De Iside et Osiride, Cambridge, 1744, and Aristotelis De poetica, Thomas Tyrwhitt (ed.), Oxonn: e typographeo Clarendoniano, 1794. Ioannis Chrysostomi de Sacerdotio, Tauchnitz, Leipzig, 1825, represents a very common style of German typesetting of the period.
} 
Greek is an early entry in a list that includes the modulated typefaces of Didot and Bodoni, and most obviously the inclined cursive styles from German type foundries.

Given the lack of adoption of Baskerville's Greek and the condemnation of the Didot style, it is not surprising that the demand for a typographically competent Greek typeface persisted. In 1806 Cambridge University Press commissioned Richard Austin to cut a typeface modelled on Richard Porson's handwriting (image 10). Porson's biographer claims that he had ' a rage for calligraphy' and that his handwriting was notable for its 'neatness and beauty', $3^{\circ}$ but it is not entirely clear that the typeface is very closely based on his handwriting. The general tone of the biography is laudatory, and is focused on Porson's literary achievements; there are comments on the quality of his handwriting, but no explicit connection with the typographic version. Mosley has highlighted the problem of making connections between individuals and the typefaces that bear their name, and has pointed to Porson (as well as Baskerville) as examples where shared names may lead to unsafe assumptions. ${ }^{31}$

Regardless of the probably tenuous - and largely irrelevant in this context - relationship between the typeface and his handwriting, it is worth examining the typeface itself. Proctor described it as 'in fact a modification of Baskerville's in the direction of legibility and simplicity' $.3^{2}$ Like Baskerville's Greek, the Porson has no ligatures, and adopts a slight inclination to the right, evoking the slant of handwriting. Unlike the Baskerville, the structure of the letters is that of slow, deliberate writing, with separate strokes and few of the fluid instrokes and outstrokes of Greek written confidently. Some stroke terminals correspond to the shapes left by a nib that is

\footnotetext{
$30 \quad$ John Selby Watson, The life of Richard Porson Longman, Green, Longman, and Roberts, London, 1863, pp. 361-362.

31 James Mosley discusses Porson's Greek in 'Porson's Greek types' , Penrose Annual, vol. 54, 1960, pp. 36-40, and 'Porson’s Greek type design' , http://typefoundry.blogspot.co.uk/2014/10/porsons-greek-type-design.html, 5 October 2014 .

32 Robert Proctor, The printing of Greek in the fifteenth century. Bibliographical Society at the Oxford University Press, 1900, p. 147.
} 
lifted vertically off the paper at the point of high pressure, leading to some peculiar shapes and inconsistent spaces between the letters. (The shapes of Baskerville's Greek are closer to the gradual lift of a pen that is tracking a continuous path to the start point of the next letter.) The Porson Greek was cut in several sizes and eventually adapted for hot-metal composition, but was only developed in one style. It was intended for a very specific category of documents, for an audience of students and classicists. In this respect, like Scholderer's New Hellenic, it was an anachronism.

None of these factors seemed to have mattered for the adoption of both Porson's and Scholderer's typefaces within their intended markets. The association with Porson's esteem as a classicist and the connection with Cambridge must have contributed significantly to the success of the typeface in classical texts. Unlike Porson and Scholderer, Baskerville's location in Birmingham and professional background, and his position as an outsider from the circles of classical scholarship, could well have stacked the odds against his Greek typeface gaining wider acceptance. Despite the nearcontemporary and later commentary, this cannot be due to the quality of his typeface - or, at least, not primarily. From a typographic perspective, it is puzzling that someone would condemn Baskerville's Greek and not find corresponding faults with both Porson and Scholderer's Greeks. 


\section{Conclusion}

With the benefit of hindsight, Baskerville's typeface represents an important experiment in the development of the Greek script from its various scribal sources towards a set of typefaces that can handle complex typographic arrangements. The lack of uptake of his approach has to be interpreted, partly at least, as a result of early timing, as well as his personal standing with the establishment for classical printing. Furthermore, it is possible that views such as Morison's were beginning to have more weight in the consideration of Greek typefaces: a year before Scholderer presented the New Hellenic, Morison wrote in 'Towards an ideal italic' : 'In England, during the same time, Baskerville, Martin, Moore, and Fry were engaged in perfecting the lines of the roman letter. They gave it open and generous proportions, but no one seems to have realised the inconsistency between their formal round roman face and their pinched calligraphic italic.

There is, in fact, a total disregard of any idea of bringing the two lowercases into association.' 33 Two years later, in his review of Jan van Krimpen's Antigone, he followed up with a pronouncement on Greek specifically: ‘ Greek calligraphy rests upon the same reasoned principles as Roman’ .34 Demonstrating the extent to which Morison's view on this matter was wrong, and the implications of his views on the Greek typefaces of van Krimpen and Gill, is a pending but achievable matter. What will remain unresolved is the effect on Greek typography that Baskerville's typeface might have had, if it had been given a better opportunity to demonstrate its merits.

\footnotetext{
33 Stanley Morison, 'Towards an ideal italic' . The Fleuron, no 5, 1926, p. 93-129

34 Stanley Morison, 'Antigone, a new Greek type' . The Fleuron, no 6, 1928, p. 186.
} 
Gerry Leonidas, A reappraisal of Baskerville’s Greek types.

Image 1

\section{K E $\Phi . \quad I A^{\prime} . \quad$ I 1 .}

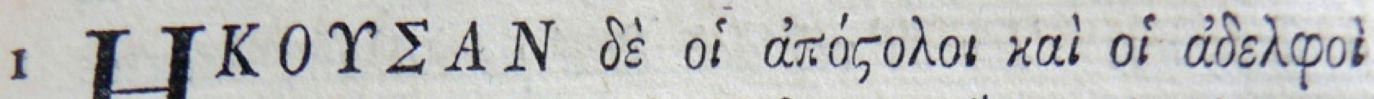

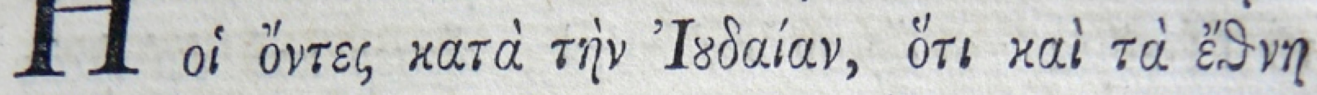

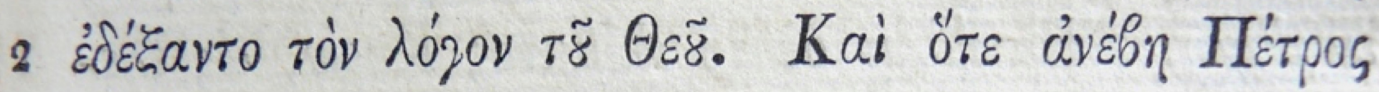

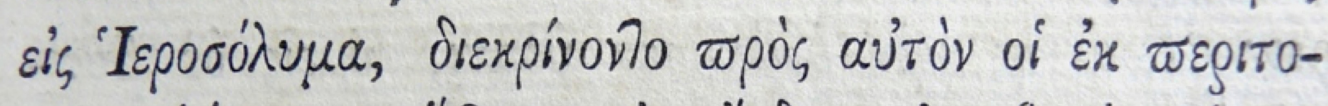

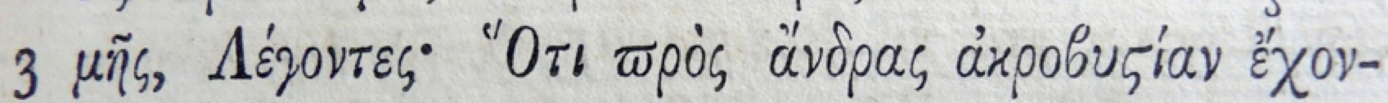

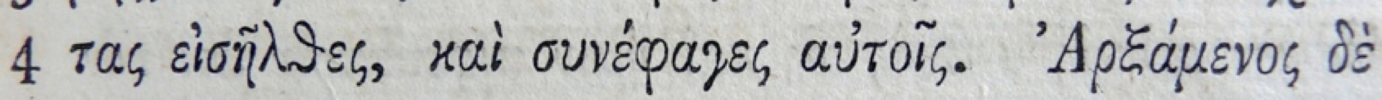

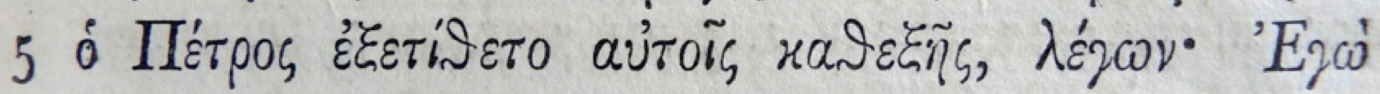

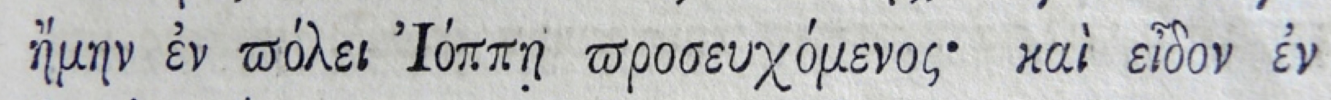

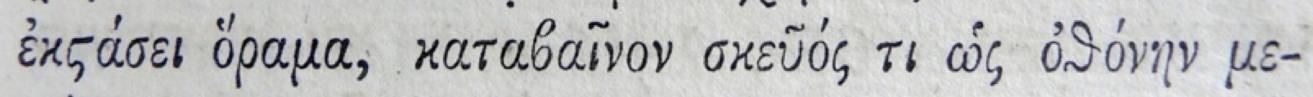

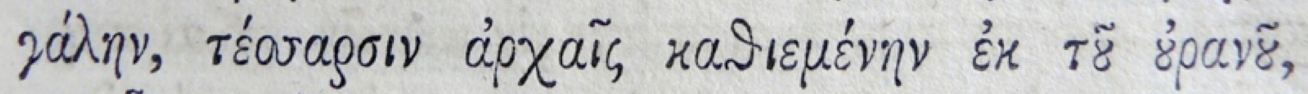

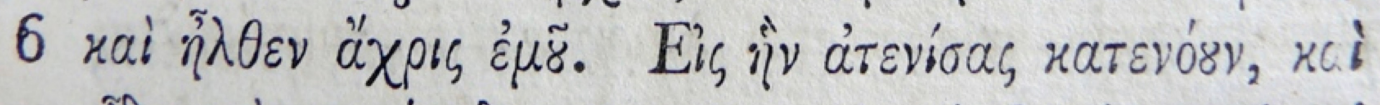

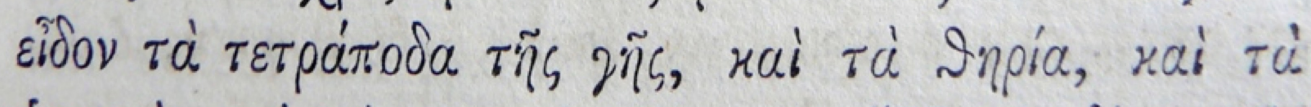

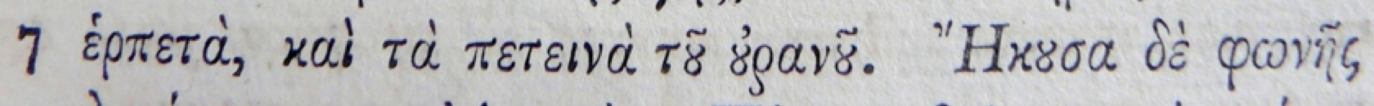


Gerry Leonidas, A reappraisal of Baskerville’s Greek types.

Image 2

\section{ПЕPI ПOIHTIKH乏.}

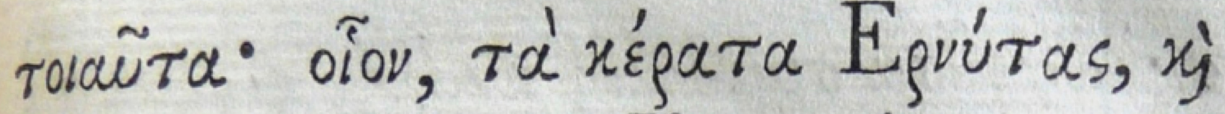

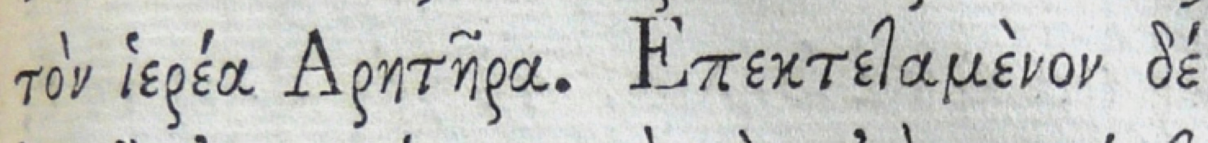

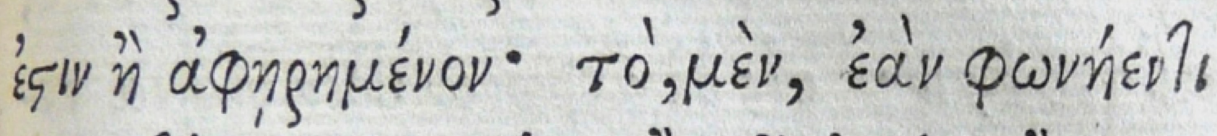

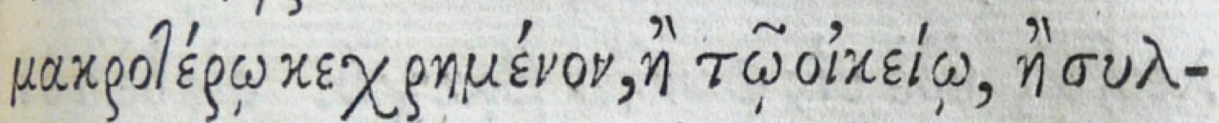

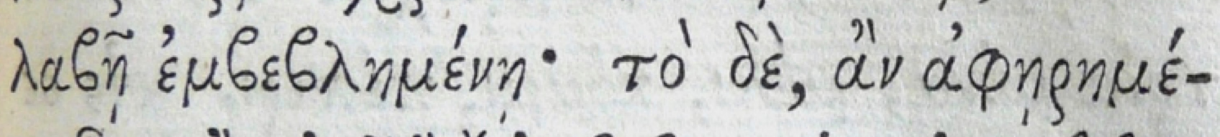

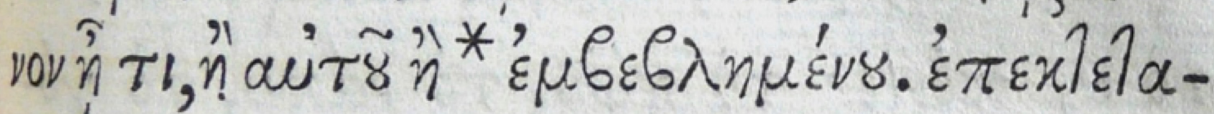

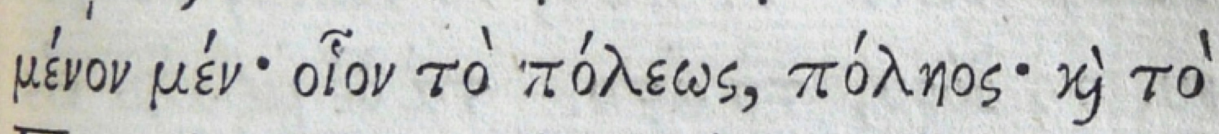

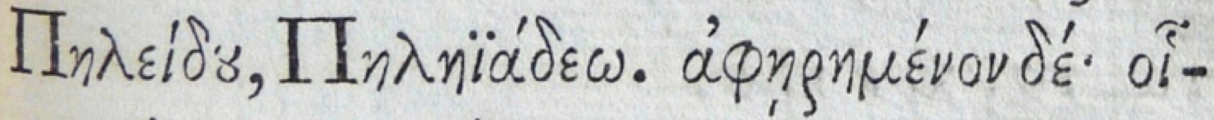
ol, $\tau 0^{\prime} x \rho \tilde{\imath}, x_{j}^{\prime} \tau 0^{\prime} \delta \tilde{\omega}^{-} x_{j}^{\prime}$,

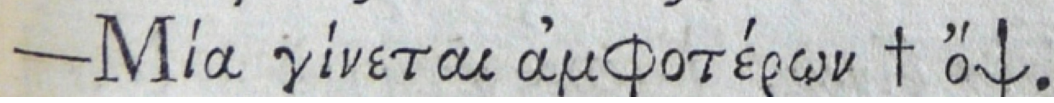


Gerry Leonidas, A reappraisal of Baskerville’s Greek types.

Image 3

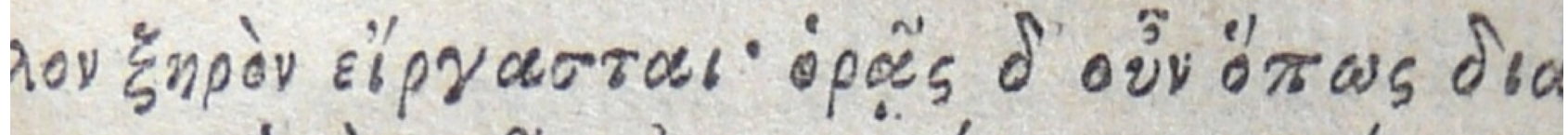

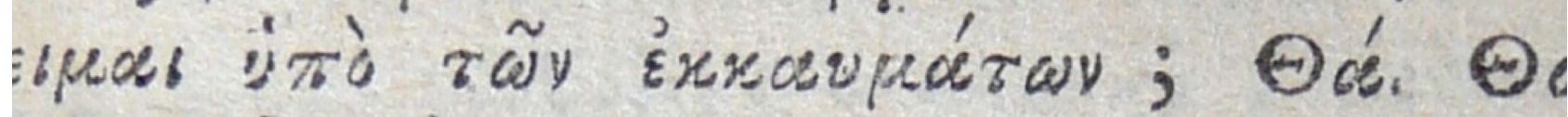

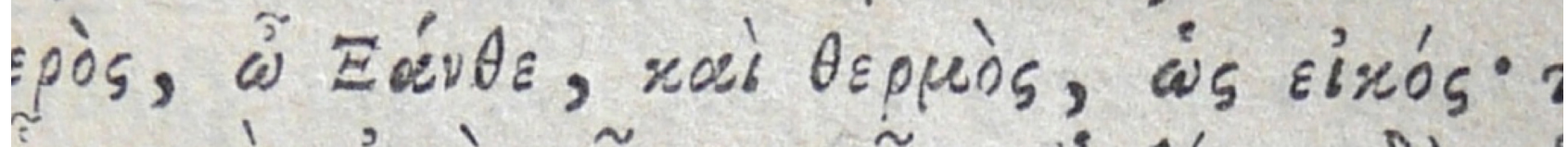

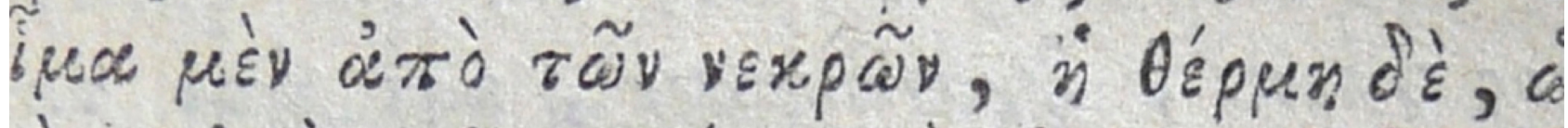

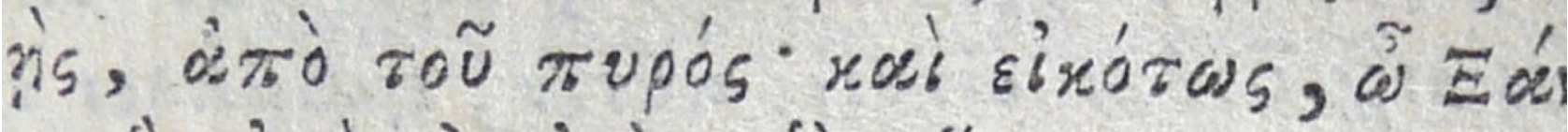

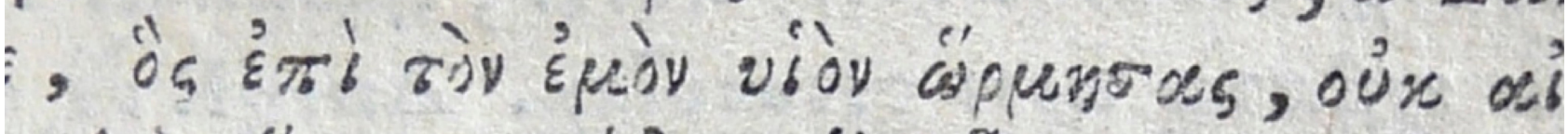

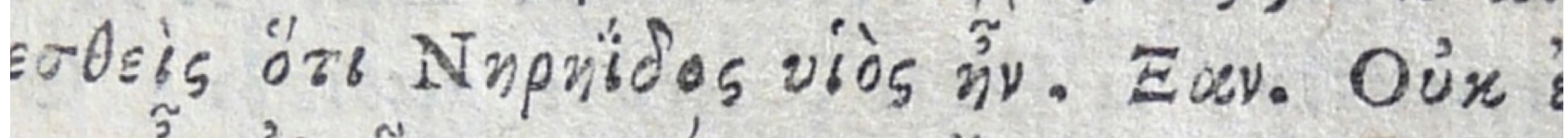

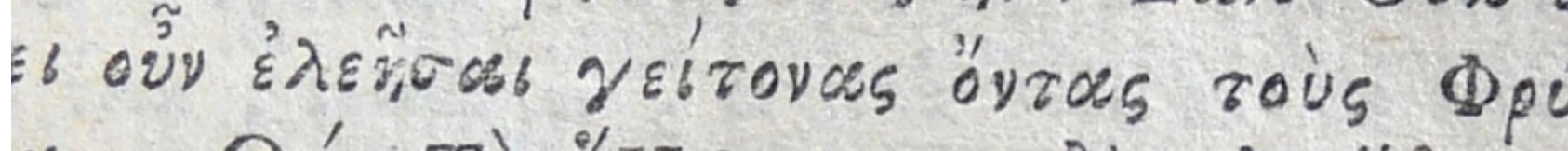

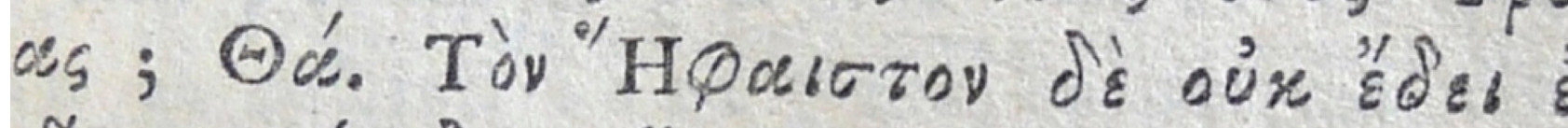

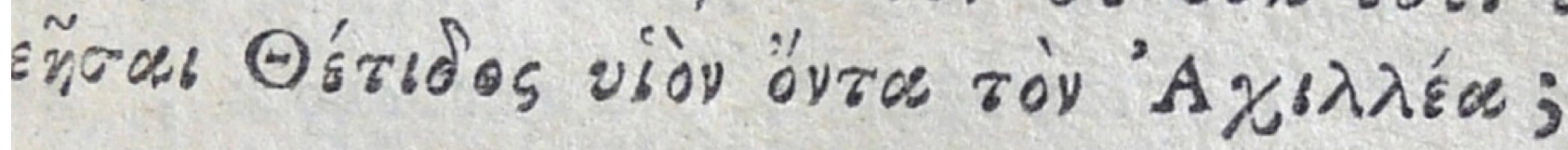


Gerry Leonidas, A reappraisal of Baskerville’s Greek types.

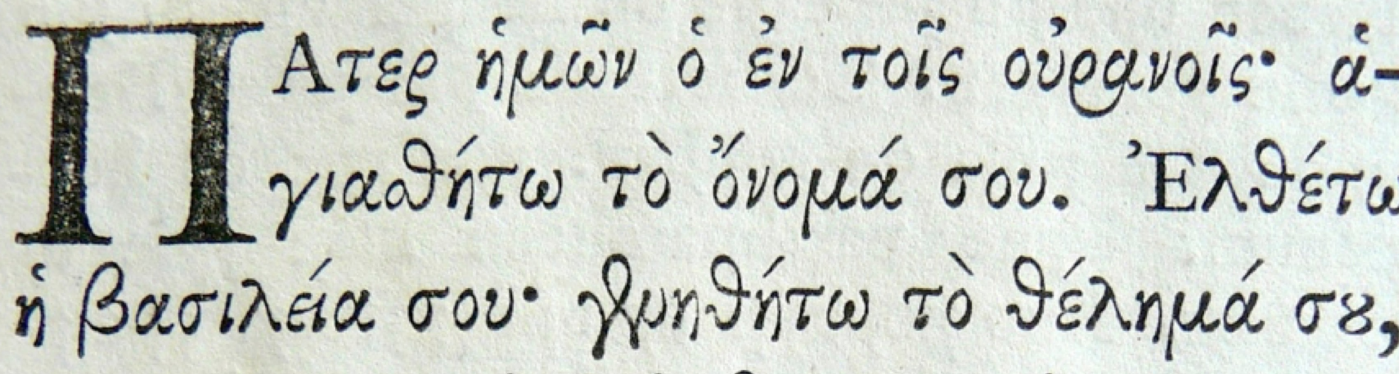

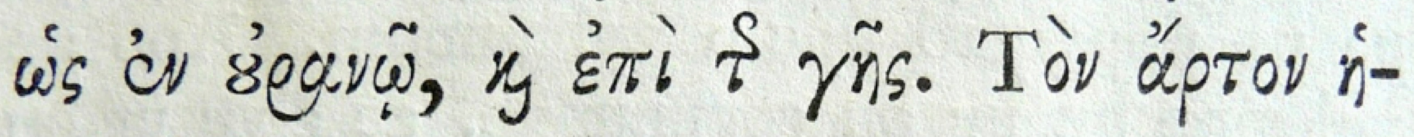

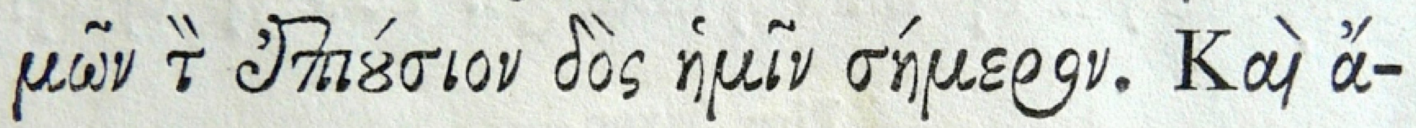

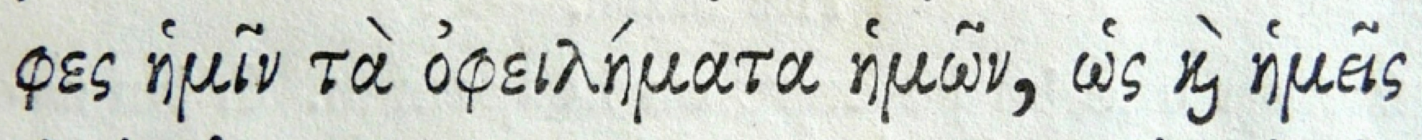

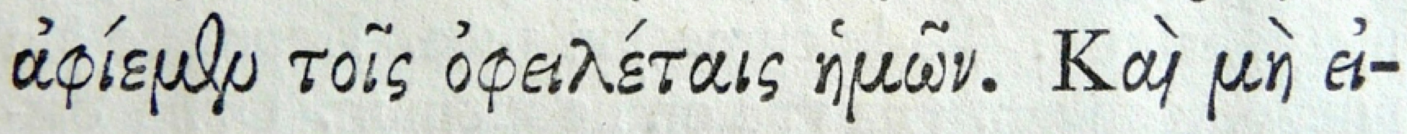

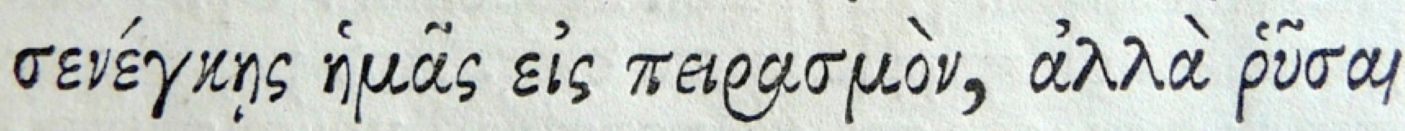

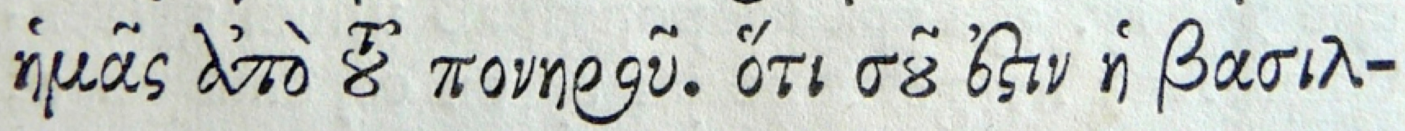

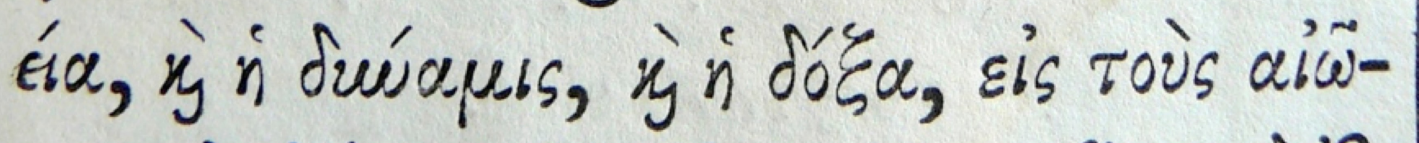
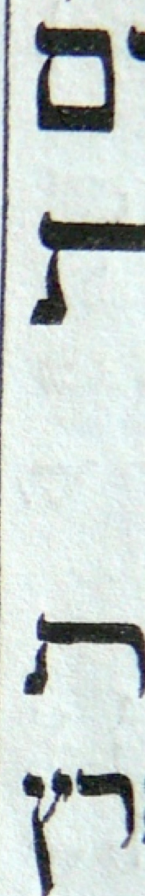

י4 979 
Gerry Leonidas, A reappraisal of Baskerville’s Greek types.

Image 5

\section{20 \\ I $\Lambda$ I A $\triangle O \mathrm{O} T$.}

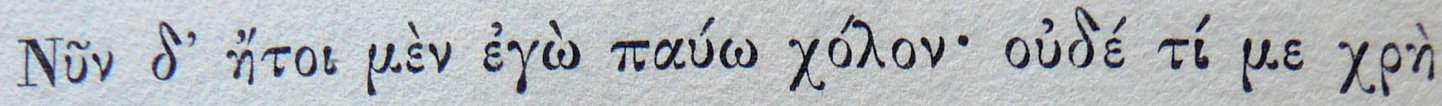

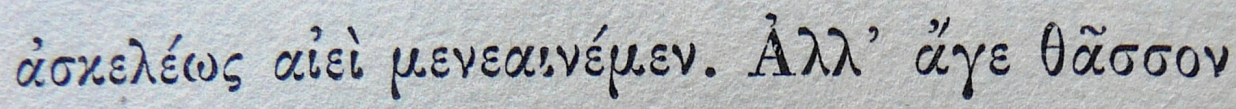

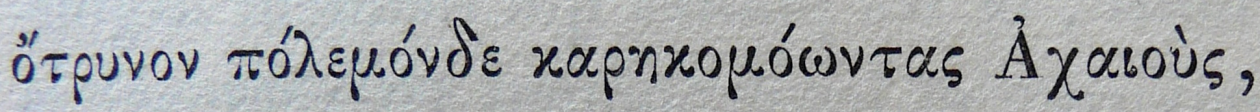

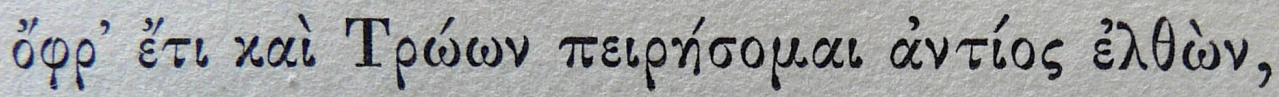

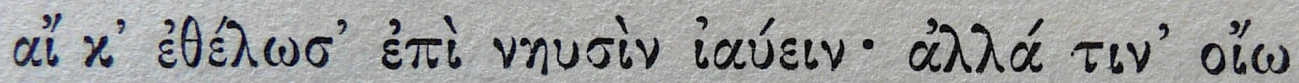

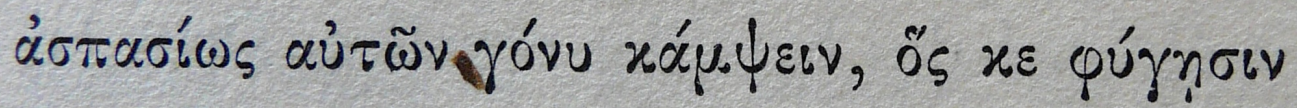

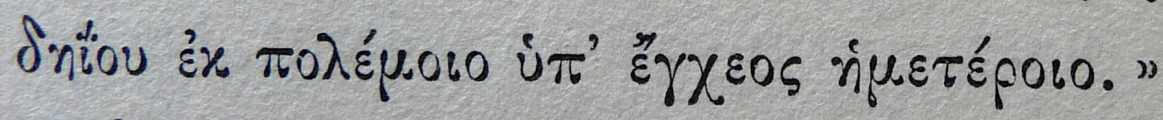

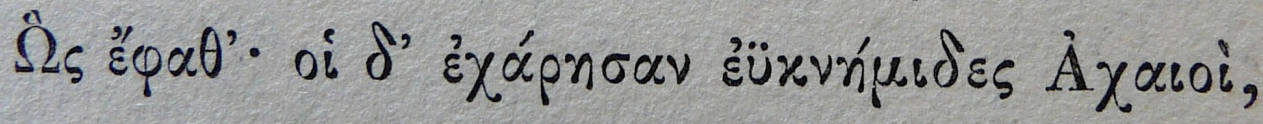

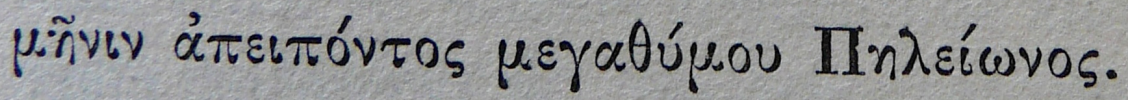

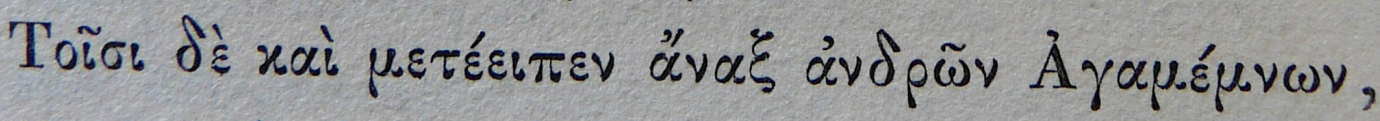

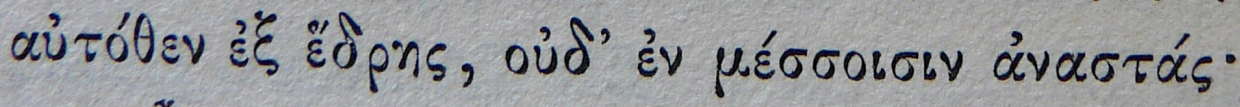

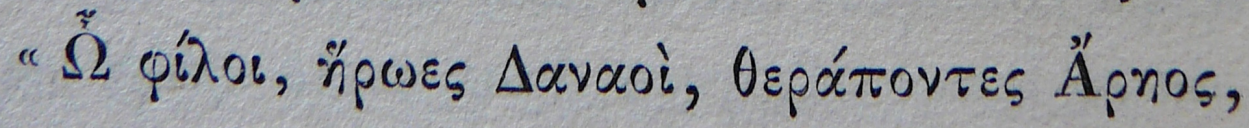


Gerry Leonidas, A reappraisal of Baskerville’s Greek types.

Image 6

$\pi$

$$
\alpha
$$

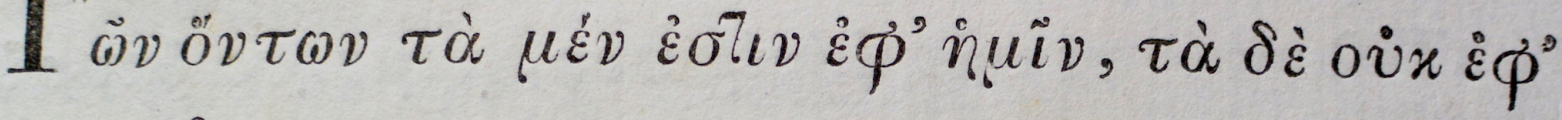

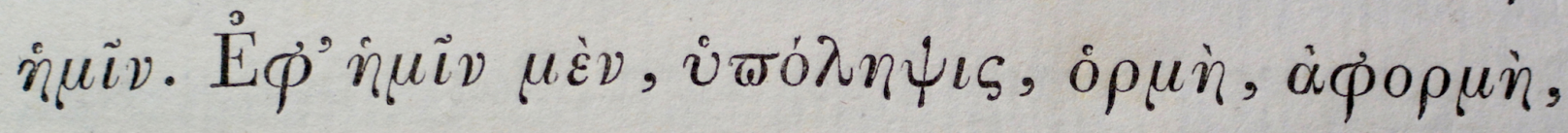

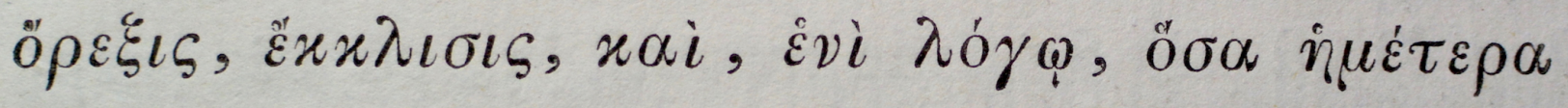
$\ddot{\varepsilon} \rho \gamma \alpha$. O $\dot{v} x \dot{\varepsilon} \dot{\phi}^{9} \dot{\eta} \mu \tilde{\imath} \nu \delta \dot{\varepsilon}, \tau \dot{o} \sigma \tilde{\omega} \mu \alpha, \grave{\eta} x \tau \tilde{\eta} \sigma \iota \varsigma, \delta o ́-$

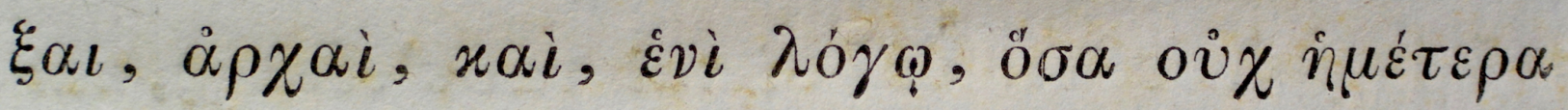
$\ddot{\varepsilon} \rho \gamma \alpha$.

$$
\beta^{\prime} .
$$


Gerry Leonidas, A reappraisal of Baskerville’s Greek types.

Image 7

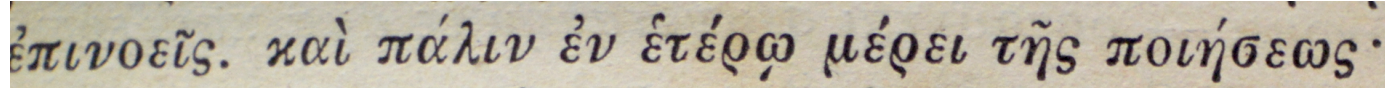

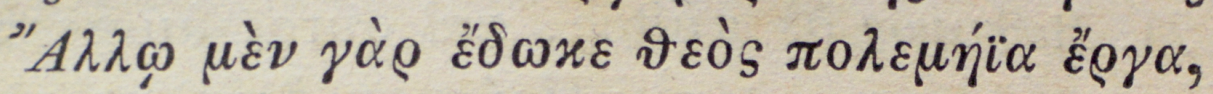

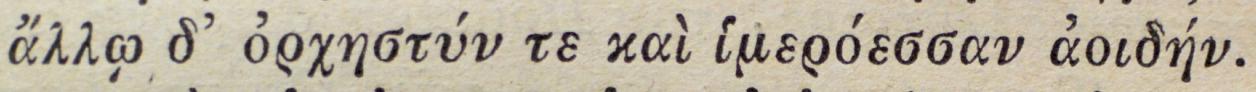

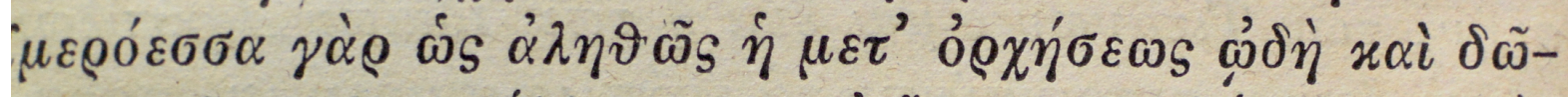

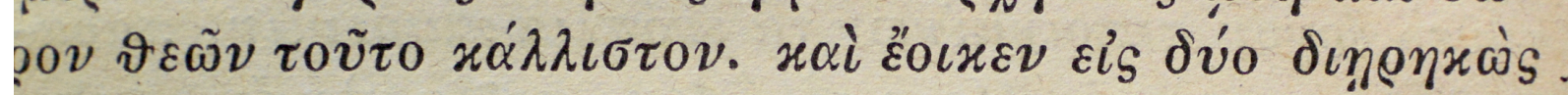
j "O

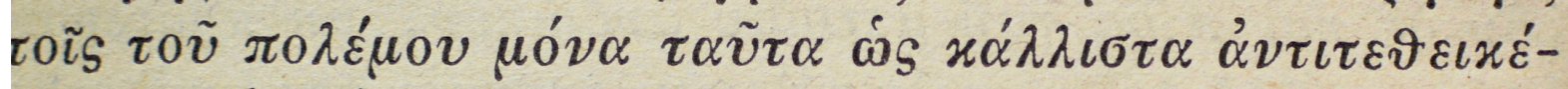

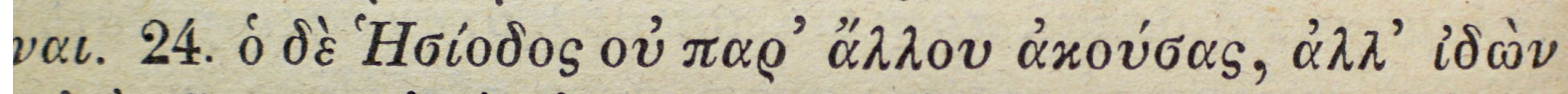

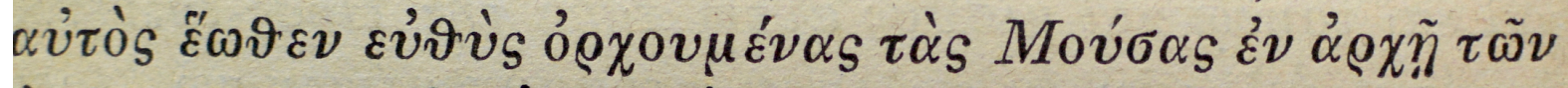

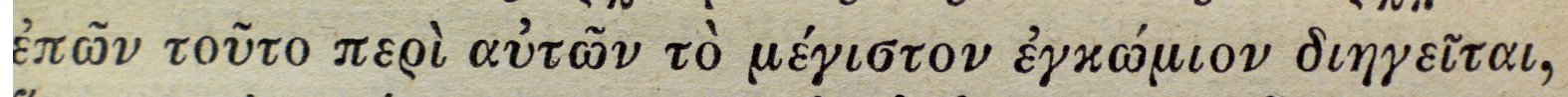

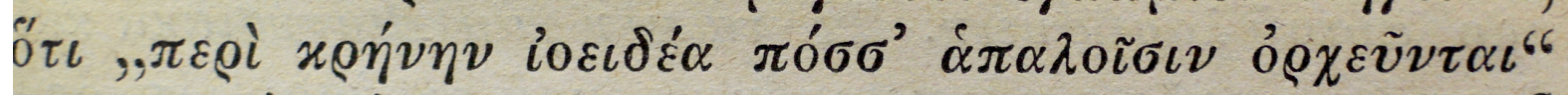

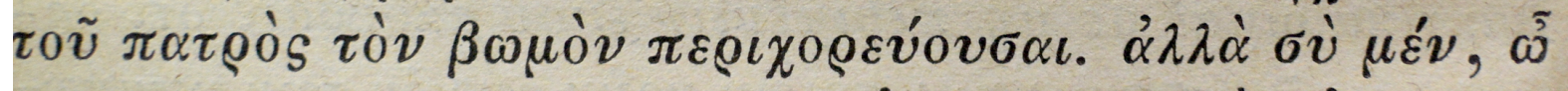

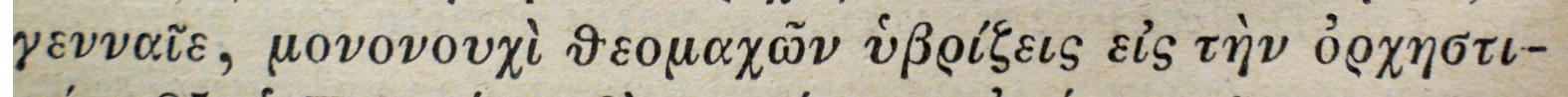

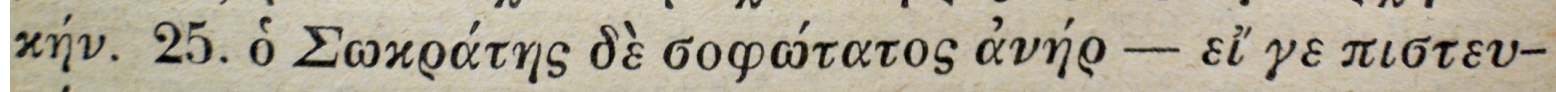

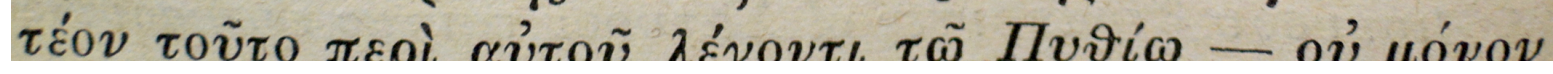


Gerry Leonidas, A reappraisal of Baskerville’s Greek types.

Image 8

\section{AICXY $\lambda$ OY XOHФOPOI OPESTHC}

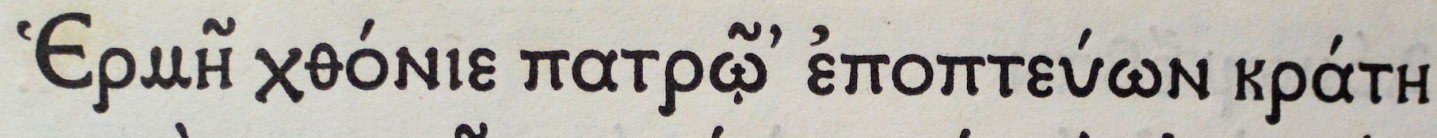

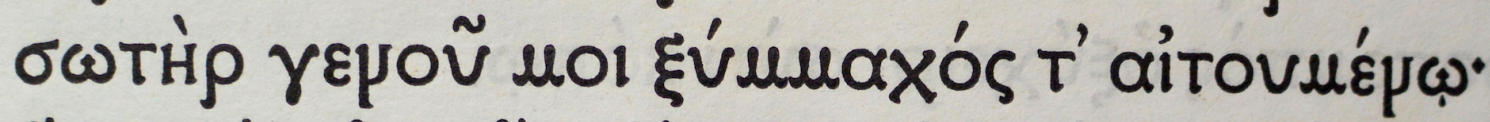

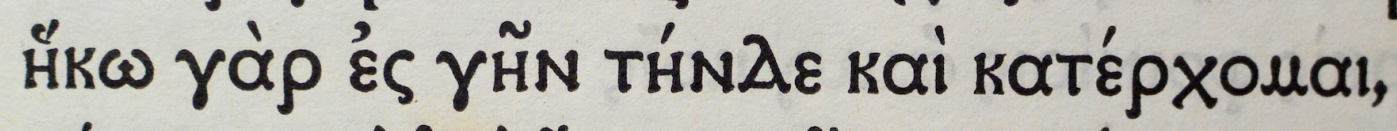

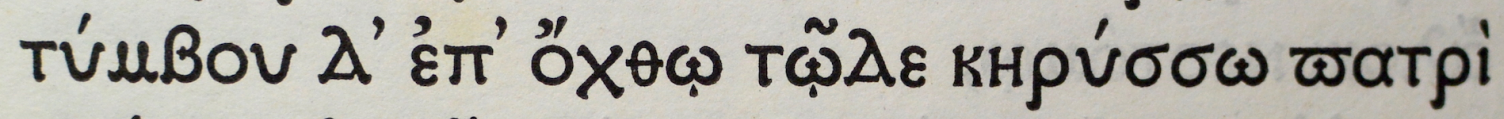

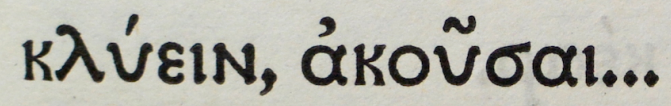

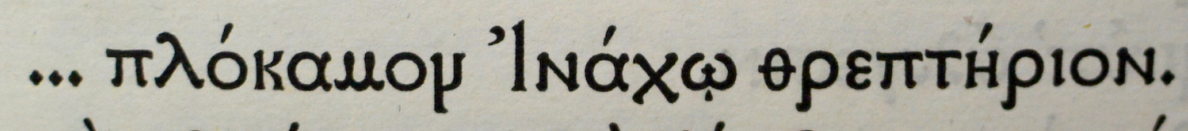

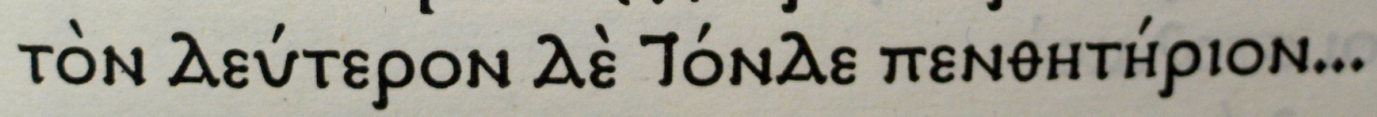


Gerry Leonidas, A reappraisal of Baskerville's Greek types.

Image 9

\section{EKTOPO $\Sigma$ KAI ANAPOMAXH $\Sigma$ OMIAIA}

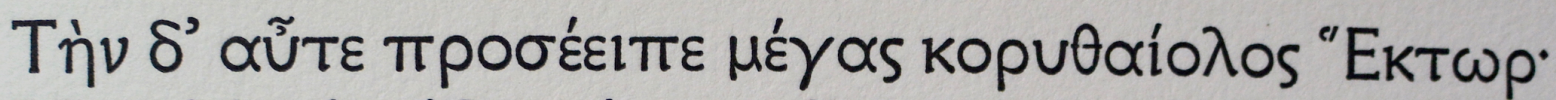

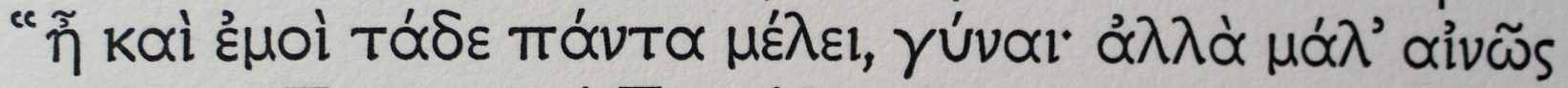

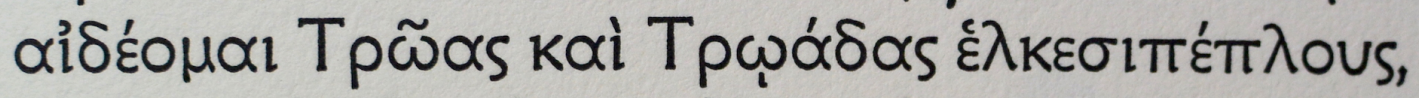

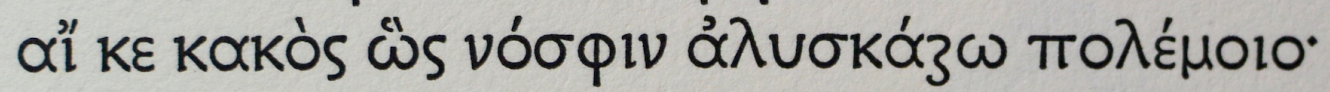

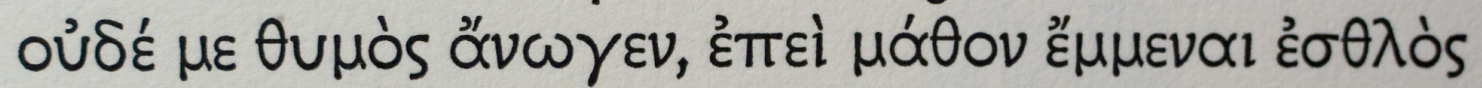

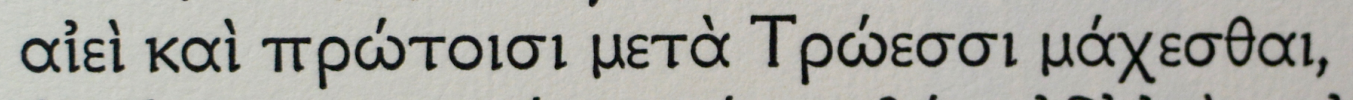

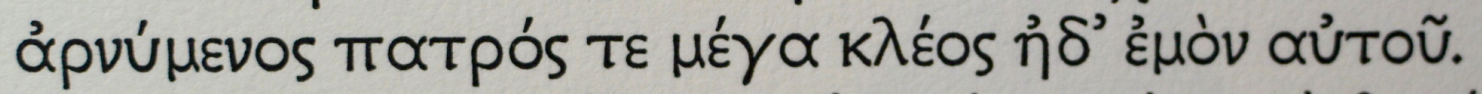


Gerry Leonidas, A reappraisal of Baskerville’s Greek types.

Image 10

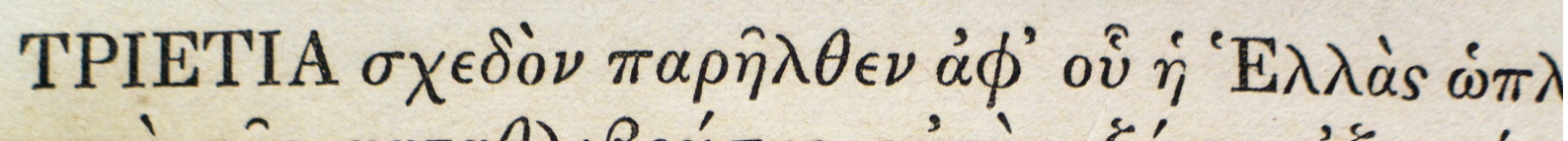

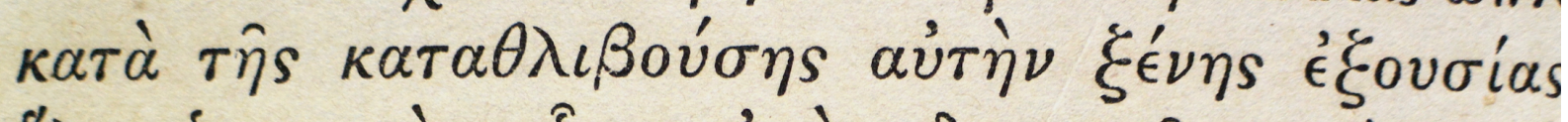

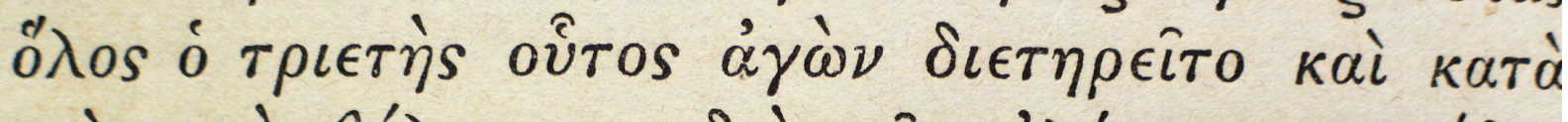

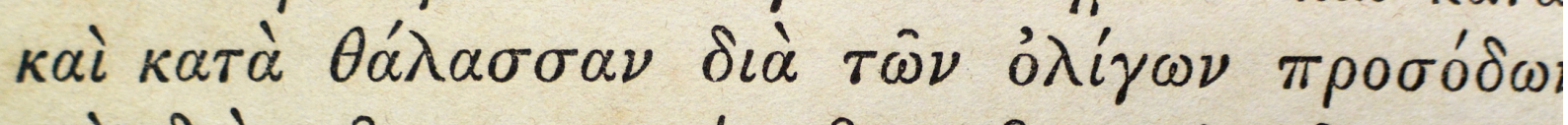

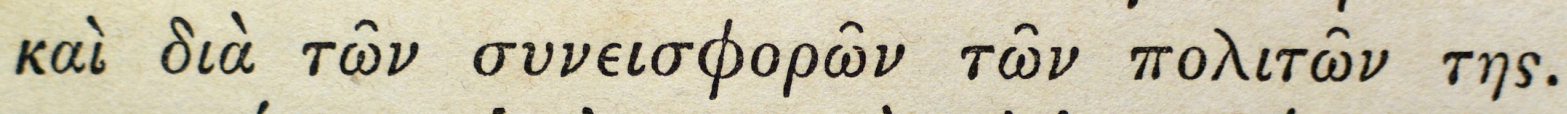

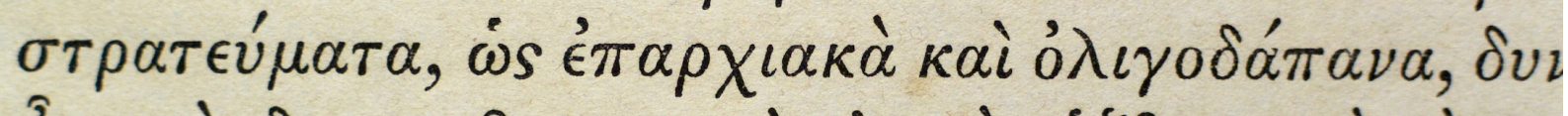

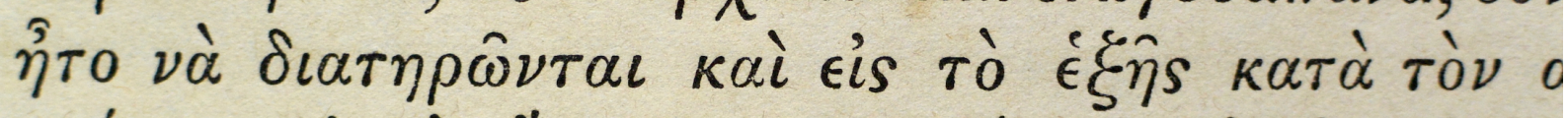

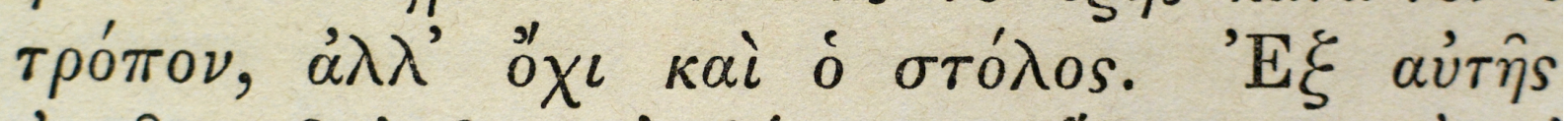

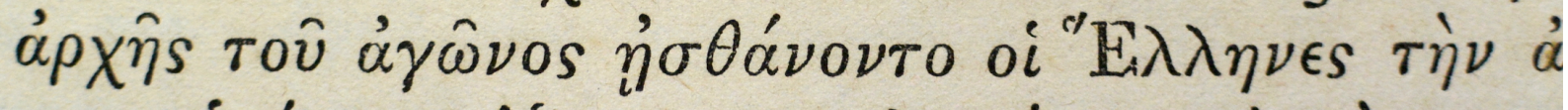

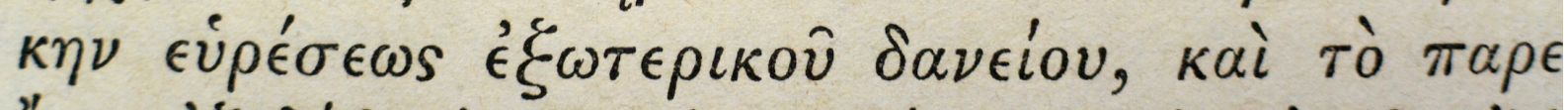

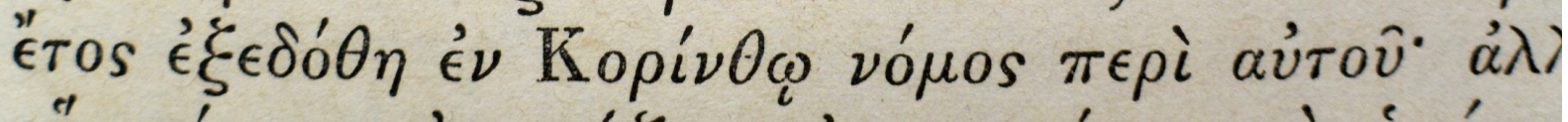

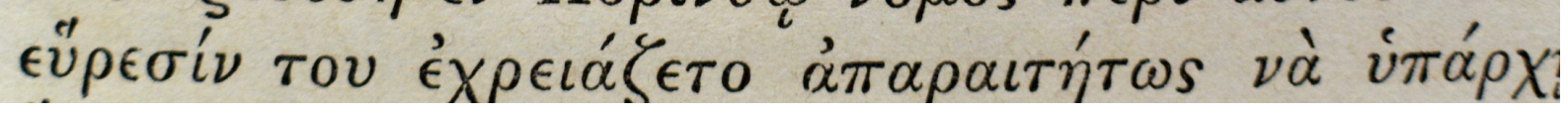

